\title{
Organizaciones de la sociedad civil en Chile: propuestas para financiamiento público y fortalecimiento institucional
}

\author{
Francisco Soto Barrientos \\ Universidad de Chile, Santiago, Chile \\ Email: fsoto@derecho.uchile.cl. \\ Felipe Viveros Caviedes \\ Universidad Bolivariana, Santiago, Chile. \\ Email: fviveros@manquehue.net
}

\begin{abstract}
Resumen: El presente trabajo analiza brevemente el marco legal de las organizaciones de la sociedad civil (OSCs) en función de las necesidades de su fortalecimiento o fomento $\mathrm{y}$, partiendo de la base que lapresencia y desarrollo de ellas un componente esencial del sistema de convivencia democrático, postula la necesidad de sus sustentación pública e identifica opciones de financiamiento público que aseguren su estabilidad y desarrollo y su interacción y cooperación con los demás sectores de la sociedad. Se afirma que, si bien la ley 20.500 de 2011 sobre Asociaciones y Participación Ciudadana en la Gestión Pública avanzó en reconocer y registrar las organizaciones de interés público, estableciendo espacios para que estas organizaciones se vinculen con ministerios, servicios y municipios y que dicha ley creó un fondo especial para el "fortalecimiento de las organizaciones de interés público", orientado a contribuir a la sustentabilidad organizacional de las OSCs, la institucionalidad legal chilena mantiene importantes deficiencias en materia de transferencias y franquicias, dispositivos que se proyectan como las principales fuentes de recursos para las OSCs en Chile.
\end{abstract}

Palabras claves: Sociedad civil, participación, cooperación, institucionalidad.

\section{Civil society in Chile: proposals for public financing and institutional strengthening}

\begin{abstract}
This paper briefly analyzes the legal framework for civil society organizations (CSOs) in light of the needs fot its empowerment or promotion and on the basis that their support is an essential component of the system and the system of democratic coexistence, seeks to identify proposals for public funding to ensure its stability and development and cooperation with other sectors of society. It is stated that while the law 20.500 of 2011 on Associations and Citizen Participation in Public Administration made progress in incorporating public interest organizations, establishing spaces for these organizations to be linked to ministries, municipalities and services, and finally the Act created a fund for the "strengthening
\end{abstract}


of organizations of public interest”, aimed at contributing to organizational sustainability of CSOs, the Chilean legal institutions has important deficiencies in transfers and franchises, devices that are projected as the main sources for CSOs resources in Chile.

Keywords: Civil Society, participation, cooperation, institutionality

\section{Organizações da sociedade civil no Chile: propostas para financiamento público e fortalecimento institucional}

Resumo: O presente trabalho analisa brevemente o marco legal das organizações da sociedade civil (OSC’s) em função das necessidades de seu fortalecimento ou fomento e, partindo da base que a presença e desenvolvimento delas representa um fator essencial do sistema de convivência democrático, postula-se a necessidade de sua sustentação pública e identifica opções de financiamento público que afirmem sua estabilidade e desenvolvimento e sua interação e cooperação com os outros setores da sociedade. Afirma-se que, se bem a lei 20.500 de 2011 sobre Associações e Participação Cidadã na Gestão Pública avançou em reconhecer e registrar as organizações de interesse público, estabelecendo espaços para que estas organizações se vinculem com ministérios, serviços e municípios e que esta lei crio um fundo especial para o "fortalecimento das organizações de interesse público", orientado a contribuir à sustentabilidade organizacional das OSC's, a institucionalidade legal chilena mantem importantes deficiências em matéria de transferências e franquias, dispositivos que se projetam como as principais fontes de recursos para as OSC's no Chile.

Palavras-chaves: Sociedade civil, participação, cooperação,instituições.

$* * *$

\section{Antecedentes y marco normativo general del asociacionismo en Chile}

El creciente protagonismo de las organizaciones de la sociedad civil (OSCs) es un fenómeno global (Salamon y otros, 2004)que, particularmente en América Latina, ha ido de la mano del proceso de democratización política. La configuración del Estado democrático no se concibe hoy en día sin la participación de las OSCs, las que en los más variados contextos han asumido un papel protagónico en la promoción de derechos humanos y en la defensa del Estado de Derecho (Seoane y otros, 2003).

Por otra parte, las OSCs se han tranformado en un actor relevante en la elaboración e implementación de políticas públicas, aportando a la transparencia y la rendición de cuentas del gobierno y fomentando una forma específica de colaboración (Pearce y otros, 2002).Clásicos estudios del Banco Mundial, entre otros, demuestran que la participación de las OSCs en políticas públicas permiten reducir costos, mostrando flexibilidad operativa y presupuestaria (Brown y Korten, 1989).

Con todo, la lógica de los programas gubernamentales se ha orientado a focalizar y canalizar los recursos públicos mediante subsidios y trans- 
ferencias hacia beneficiarios individuales, sin pasar por esquemas colectivos de intermediación. En México por ejemplo, el Programa Nacional de Solidaridad y el primer Fondo de Co-inversión Social han buscado revertir esta tendencia y aprovechar el potencial de las OSCs, elaborando esquemas de colaboración y programas para apoyar su trabajo (Verduzco y otros, 2009:4).

En Chile ha existido una tradicional presencia de OSCs en la satisfacción de nececsidades sociales y de bien público, posteriormente integrada en la implementación de políticas sociales (Salinas:1980). Como antecedentes remotos, durante el siglo XIX, destacan las "sociedades desocorros mutuos”, a través de las cuales se organizó un verdadero sistema de servicios de bienestar que funcionaba de manera paralela al Estado en materias tan relevantes como la prestación de atenciones de salud, creación de escuelas, beneficios previsionales y actividades culturales. Varios de los promotores de estas mutualidades, pertenecientes a sectores mesocráticos emergentes se involucraron políticamente desde una posición crítica del orden establecido, cuya expresiñon más notable fue la Sociedad de la Igualdad (Gazmuri,1999; Illanes, 2003). De igual manera, con sus luchas los obreros del salitre, de los ferrocarriles y los portuarios contribuyeron a las primeras regulaciones laborales y al reconocimiento de la negociación colectiva y la huelga (Viveros,2002: 437).

A partir de la segunda mitad del siglo XX, las organizaciones sociales adquieren nuevas características y cobran fuerza vinculándose al desarrollo de las comunidades locales y de los habitantes de sectores urbanos pobres(Salazar, 2012). Avanzado el siglo, prueba del importante trabajo desplegado por las OSCs en el mundo popular en la década de los sesentas, en el marco de las políticas gubernamentales de "Promoción Popular" se elabora y se dicta la Ley 16.880, del 7 de agosto de 1968, sobre Juntas de Vecinos y Organizaciones Comunitarias, que reconoció a las organizaciones vecinales de carácter territorial y funcional, a sus uniones comunales y federaciones de grado superior, y dotándolas de un conjunto de funciones y atribuciones en el ámbito local, con capacidad de interlocución formal con las autoridades municipales (Silva, 1997; Soto: 2013).

Siguiendo una tendencia latinoamericana, las OSCs ocuparon en Chile, durante los años ochentas,un papel clave en la recuperación de la democracia y en la propuesta de alternativas para su implementación y, por ende, en el diseño y aplicación de las políticas públicas de los últimos 30 años. Hoy las OSCs se han transformado en un importante actor de la economía chilena, pues emplea en forma remunerada y voluntaria a 303.000 personas en jornada completa. Si solo se considera el empleo remunerado, este representa al 2,6\% de la población económicamente activa. El tamaño relativo de las OSCs en términos de gastos, representan un 1,5\% del PIB, es decir, US\$1.408,9 millones, lo que lo convierte en uno de los más significativos de la región (Irarrázaval y otros, 2006).

Al carácter cada vez más complejo del mundo asociativo chileno se ha sumado una creciente legislación regulatoria con intención muchas ve- 
ces de promoverlas y apoyarlas a su inserción social. Contrario a lo que se pudiera pensar, desde la propia experiencia de las OSCs estos afanes regulatorios no han contribuido al desarrollo y buen funcionamiento de las mismas en Chile. El informe del PNUD del año 2000 concluyó enfatizando dificultades en su institucionalización y consideró como prioritario establecer reformas legislativas. Se refiere a una sociedad civil que pese a tener un potencial asociativo significativo, adolece de dificultades para relacionarse entre pares y para constituir redes de colaboración(PNUD, 2000).

Con el objetivo de corregir algunas de las deficiencias descritas, en junio de 2004 se presentó al Congreso el proyecto de ley de asociacionismo y participación en la gestión pública, ofrecido en el programa presidencial de Ricardo Lagos. Lo anterior dio lugar finalmente a laLey 20.500, promulgada casi once años después, el 16 de febrero de 2011. Esta ley configura un nuevo escenario para la asociatividad ciudadana en Chile. Aunque se la podría calificar como una "ley miscelánea”, dado que establece un conjunto de regulaciones nuevas sobre diversas materias y, además, modifica diversos cuerpos legales, es posible distinguir en ella dos ejes fundamentales: por una parte, i) el reconocimiento del derecho de asociación y un conjunto de dispositivos de fomento de determinadas organizaciones (llamadas por la ley “organizaciones de interés público”, que incluye entre ellas a las fundaciones y corporaciones con objetivos de beneficio público, a las organizaciones de voluntarios, a las organizaciones comunitarias y a las organizaciones indígenas); y por otra, ii) mecanismos de participación ciudadana en la administración central y descentralizada del Estado y en los municipios, que incluye en primer lugar, el reconocimiento del principio jurídico administrativo de participación ciudadana y el derecho de las personas a participar en la gestión pública y, luego, el deber de los órganos estatales de dictar normas generales u ordenanzas de participación ciudadana, de crear consejos de sociedad civil de carácter consultivo, además de precisar normas sobre información pública, mecanismos de consultas ciudadanas y cuentas públicas participativas y abrir la opción de otros mecanismos de participación no nominados o apenas nominados en la ley, como es el caso de los presupuestos participativos en los municipios(Soto, 2013).

\section{Fortalecimiento institucional de las organizaciones de la sociedad civil}

De acuerdo con los datos disponiles, en los años recientes la mayor parte del financiamiento de las OSCs en Chile ha estado constituida por transferencias del sector público (46\% de los ingresos) y por franquicias (18\%). El 36\% restante proviene de ingresos propios, como cuotas de asociados y prestaciones de servicios(Irarrázaval y otros,2006).

Un elemento común entre las tranferencias y las franquicias en el diseño institucional chileno es su dispersión en la legislación y el aparato público y en la caracterización del tipo de instituciones que beneficia. Con 
todo, tanto la doctrina legal como el Tibunal Constitucional chileno han establecido que la regulación público-administrativa que compete a todas las transferencias, subvenciones y franquicias otorgadas por el Estado se deben regir por tres principios fundamentales: el principio de legalidad, el principio de igualdad y el principio de transparencia (García, 2012).

Por nuestra parte, estimamos que se deben considerar también como principios regulatorios de esta materia la participación ciudadana, la colaboración y el fortalecimiento de la organizaciones de interés público, establecidos en la Ley 20.500. Las ideas de la participación y de la colaboración se amparan en la bases de la institucionalidad recogidas en el artículo $1^{\circ}$ incisos quinto y tercero de la Constitución Política, respectivamente. La participación encuentra fundamento expreso en el referido inciso quinto que consagra como deber del Estado “asegurar el derecho de las personas a participar con igualdad de oportunidades en la vida nacional” (art. 1, inciso 5). Por su parte, el inciso tercero señala: "El Estado reconoce y ampara a los grupos intermedios a través de los cuales se organiza y estructura la sociedad, y les garantiza la adecuada autonomía para cumplir sus propios fines específicos” (art. 1, inciso 3). El Tribunal Constitucional en la sentencia $N^{\circ} 1259$, de 2009, señaló, en su considerando 57, que entiende la Constitución por "reconocer y amparar. Declarando al respecto: "el reconocimiento implica que [la entidad] puede existir sin su intervención y el derecho de asociación que la constitución garantiza para crear todo tipo de agrupaciones es “sin permiso previo” (artículo 19 N 15). Incluso cuando alguna de estas asociaciones obtiene su personalidad jurídica, es por el solo hecho de depositar sus actas constitutivas en los registros que lleva algún órgano del Estado. El amparo, por su parte, implica que

"Pueden hacer valer en defensa de sus derechos todos los recursos y acciones que propendan a hacerlos efectivos [..También implica..] La obligación del Estado de protegerlos, colaborar con ellos y, con sujeción al principio de subsidiaridad, ayudarlos y fomentar su existencia y desenvolvimiento” (Fallo del Tribunal Constitucional rol N 1295, del 6 de octubre de 2009, considerando 57)

En este sentido, la Ley 20.500 aporta sustancialmente al derecho chileno la concreción y desarrollo normativos de la asociatividad civil, al identificar significativamente a los grupos intermedios de la sociedad con las organizaciones de interés público que colaboran en la gestión pública de los ministerios, servicios y municipalidades. Lo que nos agrega las citadas disposiciones constitucionales y la sentencia $\mathrm{N}^{\circ} 1259$ es que el Estado no sólo debe someter su apoyo a estas organizaciones bajo los principios de legalidad, igualdad y transparencia, sino que además se resguarda constitucionalmente la necesidad de velar por la subsistencia de ellas bajo los estándares de la participación y de la colaboración. Esto último tiene plena conexión con la reflexión comparada sobre el fortalecimiento de la sociedad civil, a la cual aluden las experiencias de Brasil y México, destacadas entre las de varios países de la región. 
La interpretación antes señalada, que sitúa y dimensiona la relación político jurídica entre el Estado y los grupos intermedios, supone un distanciamiento frente a dos tesis altamente ideólogicas que han dominado el debate constitucional chileno desde los años setenta. La primera, que supuso dar un rol de vanguardia en la acción política al movimiento popular, se manifestó durante el período de la Unidad Popular a través de organizaciones que tendían a generar un poder social o “popular” paralelo al Estado, y fue contrarrestada, al menos en el nivel normativo, a través de la reforma constitucional de enero de 1971, que agregó un numeral 17 al artículo 10 de la Constitución de 1925, consagrando "el derecho a participar activamente en la vida social, cultural, cívica, política y económica con el objeto de lograr el pleno desarrollo de la persona humana y su incorporación efectiva a la comunidad nacional” (Soto, 2013:199). Esta garantía comprendía el deber del Estado de remover los obstáculos a la libertad e igualdad de las personas y grupos, su acceso a la educación y a la cultura y a los servicios necesarios para conseguir esos objetivos. Asimismo, se aseguraba la independencia de las organizaciones sociales para generar democráticamente sus organismos directivos y se establecía categóricamente que en ningún caso esas instituciones podrán arrogarse el nombre o representación del pueblo, ni intentar ejercer poderes propios de las autoridades del Estado.

Por otra parte, durante la dictadura y desde la comisión de estudios para la nueva Constitución que dicho régimen propiciaba, se fue estructurando una teoría que derivó en la redacción del inciso $3^{\circ}$ del artículo $1^{\circ}$ de la Constitución de 1980, cuya interpretación “originalista” ha pretendido ver en este pasaje y en otros del texto constitucional, cuando no en su "historia fidedigna", un supuesto principio de subsidiaridad que finalmente le ha dado sustento ideológico al modelo neoliberal prevaleciente en la actual Constitución (Cea, 1999: 171-175). ${ }^{1}$

Desde la perspectiva de los derechos fundamentales, cabe agregar una nota adicional de particular interés en relación con el derecho de asociación reconocido en los instrumentos internacionales de derechos humanos y también en la Constitución y legislación chilenas (art. 19 N N $^{\circ} \mathrm{CPE}$ y arts. $1^{\circ}$ a $7^{\circ}$ Ley 20.500). La Ley 20.500 estableció expresamente como deber del Estado "promover y apoyar las iniciativas asociativas de la sociedad civil” (art.2), imperativo que si bien no se refiere explícitamente a apoyo económico o financiero, evidentemente no lo excluye, por lo que el intérprete y aplicador de la ley ha de entender que dicha disposición incluye los apoyos económicos entre las diversas formas posibles de ayuda estatal a las OSCs. A mayor abundamiento, la referida norma agrega otro deber: “el Estado, en sus programas, planes y acciones, deberá contemplar el fomento de las asociaciones, garantizando criterios técnicos objetivos y de plena transparencia en los procedimientos de asignación de recursos” (art.2, inciso 3 ).

Lo anterior conecta con recientes desarrollos del derecho internacional. Al efecto, el Relator Especial de Naciones Unidas sobre los Derechos a la Libertad de Reunión Pacífica y de Asociación, en su Informe de 
2012, reafirma el derecho de acceso a financiación y recursos de las asociaciones, y que esta posibilidad "es parte integrante y vital del derecho a la libertad de asociación”. Por tanto, todas las asociaciones, estén o no registradas legalmente, "deben disfrutar del derecho a recabar y obtener financiación de entidades nacionales, extranjeras e internacionales, incluidos particulares, empresas, organizaciones de la sociedad civil, gobiernos y organizaciones internacionales.” (Informe 2012, Relator ONU).

En consecuencia, la idea de asegurar el financiamiento público de las OSCs como una responsabilidad del Estado se funda en la debida artículación de los principios indicados y en reconocer la primacía del amparo, en el sentido de la colaboración y el fortalecimiento de la sociedad civil.

\section{Financiamiento a través de fondos y subvenciones del sector público}

Una de las demandas largamente planteadas por el sector de las organizaciones de la sociedad civil chilena desde la década de los noventas, fue el establecimiento de un fondo que asegurara, bajo condiciones de suficiencia, universalidad y equidad, el desarrollo institucional del sector, que contara con un presupuesto propio significativo y que pudiera ser dirigido y asignado mediante una gestión pluralista y participativa por las propias organizaciones que integran este sector (De La Maza, 2005).

El diagnóstico se fundamentó en la dispersión de los fondos existentes, generalmente dirigidos a iniciativas de corto plazo, la mayoría de ellos entre seis meses y un año, que implicaban ejecución de programas estatales predefinidos y el consecuente acotamiento de las OSCs participantes a un rol de provisión de servicios públicos por encargo o delegación estatal. Muchos han calificado esta modalidad como simple terciarización de servicios estatales, agravada por los bajos aportes y subvenciones determinados como contraprestación, y por la virtual restricción, si no anulación, del potencial participativo, innovador y de gestión y formulación autónoma de las OSCs. Esta modalidad de financiamiento, generalizada en el trato de la administracion pública hacia las OSCs, obligó a las organizaciones a perder sus especializaciones y a tener que diversificar sus estrategias de sobrevivencia para poder conseguir recursos de más de una fuente o fondo.

Con el propósito de avanzar en la superación de este problema endémico, la Ley 20.500 creó el Fondo de Fortalecimiento de las Organizaciones de Interés Público (artículos. 21 a 31) que cuenta con recursos asignados por la ley de presupuesto y con un Consejo nacional y con consejos regionales que definen políticas de elegibilidad y criterios y objetivos para la asignación de los recursos. Dichos consejos son en parte elegidos por las propias organizaciones de la sociedad civil. 
Al corto andar de este fondo las críticas se han sucedido. Paradójicamente ahora que el fondo tiene fundamento legal (antes de la ley, se constituyó y funcionó por casi una década con fundamento en resoluciones administrativas) no ha funcionado porque las autoridades han demorado en constituir el consejo que lo administra. Pero las observaciones de fondo se orientan a la incapacidad del modelo propuesto por la ley de establecer un sistema de sustentación estable para las OSCs y una instancia de coordinación de los distintos mecanismos que en ella se reconocen. En lo que se refiere al fortalecimiento de la sociedad civil, el fondo de fortalecimiento creado mantiene los rasgos estructurales de cualquier fondo concursable, en especial la "lógica de proyectos", el cortoplacismo, la rigidez de objetivos y la miopía hacia las necesidades institucionales de organizaciones que en general son frágiles desde el punto de vista financiero, con el agravante de su significación cualitativamente menor que la de otros fondos existentes, todo lo cual comprobadamente no asegura la sustentación de las OSCs, sino que las tensiona en torno al cumplimiento de burocracias y resultados preferentemente formales, o de requisitos y rendiciones de cuentas desproporcionados o, incluso, activando procesos sociales virtuosos que al corto tiempo quedan truncos por falta de continuidad.

La insuficiencia del Fondo de Fortalecimiento de las Organizaciones de Interés Público para resolver los crecientes problemas de sustentabilidad de las organizaciones queda en evidencia en un reciente estudio sobre los mecanismos públicos de financiamiento para las organizaciones de la sociedad civil en Chile, donde el referido fondo representa un 0,09 por ciento de los recursos transferidos por el Estado este tipo de organizaciones durante el período 2007 - 2013 y sólo un 6 por ciento de los recursos entregados bajo el mecanismo de fondos concursables para el mismo período de tiempo (Sánchez y otros, 2015).

Sobre este particular puede resultar aleccionadora la experiencia comparada. Algunos países han avanzado en una modalidad nueva de vinculación de las OSCs con el Estado, en una línea de alianzas estratégicas que resguardan la identidad, autonomía, lógica de funcionamiento y razón de ser de cada uno de los polos involucrados, en particular del polo generalmente más débil, esto es, las OSCs. Fuera de nuestra órbita geográfica y cultural, se puede traer a colación con bastante provecho la experiencia de creación de fondos públicos en países como Hungría, el Reino Unido, Croacia y Macedonia (TACSO, 2011), en los que destacan opciones como las siguientes:

- Financiamientos de mediano y largo plazo, con recursos para que las OSCs desarrollen proyectos plurianuales.

- Flexibilización y apertura a co-financiamientos o aportes de recursos propios en bienes y servicios o reserva para capitalización de parte de los recursos aportados por el fondo público.

- Apertura a líneas de financiamiento no discriminatorias de OSCs 
con clara misión de advocacy o promoción de derechos y causas ciudadanas (y, por tanto, no estrictamente "prestadoras de servicios” o ejecutoras de programas predefinidos por el órgano estatal), sin prejuzgar su eventual colisión con los intereses de los gobiernos. Lo que implica que el Estado puede perfectamente apoyar dinámicas de deliberación democrática impulsadas por OSCs críticas o contestatarias, en el marco del estado de derecho.

- Definición de apoyos económicos para proyectos en áreas o materias determinados (la línea usual) con gastos de administración reconocidos y, por otra parte, apoyos económicos para el desarrollo institucional de las OSCs propiamente tal.

En América Latina y Chile el panorama en estas líneas es débil y heterogéneo. Con todo, esta perspectiva de alianzas estratégicas ha sido tomada por las OSCs y gobiernos de México y Brasil principalmente. El primero con la Ley Federal de Fomento de las Actividades de las Organizaciones de la Sociedad Civil, el segundo, avanzando lo que en Brasil se ha llamado una "tercera fase” de la participación ciudadana en la construcción del Marco Regulatorio de las Organizaciones de la Sociedad Civil, denominada de “contractualización”.

La Ley Federal de Fomento mexicana (LFOSC), dictada en el año 2004, constituye un gran marco jurídico para el desarrollo de las OSCs, que les permite utilizar mecanismos, dispositivos y beneficios que fueron legalmente consensuados y fruto de un largo trabajo de incidencia legislativa llevado a cabo por las OSCs mexicanas. La ley se articula explícitamente sobre tres ejes: transparencia, rendición de cuentas y corresponsabilidad. No garantiza recursos, pero en el complejo contexto del país, ha servido de base para el reconociendo social, político y jurídico de las OSCs en el nivel federal y en los niveles estaduales, y asegurar su actuación legitimada y en expansión en la vida pública.

La LFOSC define pormenorizadamente las áreas de actividades susceptibles del fomento legal: asistencia social, apoyo a la alimentación popular, actividades cívicas enfocadas a promover la participación ciudadana en asuntos de interés público, asistencia jurídica, apoyo para el desarrollo de los pueblos y comunidades indígenas, promoción de la equidad de género, servicios para la atención a grupos sociales con discapacidad, cooperación para el desarrollo comunitario en el entorno urbano o rural, apoyo en la defensa y promoción de los derechos humanos, promoción del deporte, promoción y aportación de servicios para la atención de la salud y cuestiones sanitarias, apoyo en el aprovechamiento de los recursos naturales, la protección del ambiente, la flora y la fauna, la preservación y restauración del equilibrio ecológico, así como la promoción del desarrollo sustentable a nivel regional y comunitario, de las zonas urbanas y rurales, promoción y fomento educativo, cultural, artístico, científico y tecnológico, fomento de acciones para mejorar la economía popular, participación en acciones de protección civil, servicios de apoyo a la creación y fortalecimiento de orga- 
nizaciones, promoción y defensa de los derechos de los consumidores, acciones que promuevan el fortalecimiento del tejido social y la seguridad ciudadana, y las que determinen otras leyes.

La LFOSC creó tres órganos: i) la Comisión de Fomento, encargada de definir el diseño, ejecución, seguimiento y evaluación de acciones y medidas para el fomento de las actividades que realizan las OSCs señaladas en la ley, así como la definición de mecanismos para la participación de las OSCs en las políticas públicas; ii) el Registro de Organizaciones de la Sociedad Civil, voluntario y gratuito para todas las OSCs que deseen acogerse a la ley y que, en general, las habilita para postular a recursos públicos; y iii) el Consejo Técnico Consultivo como órgano de asesoría y consulta, de carácter honorario, representativo de la diversidad de OSCs, que tiene por objeto proponer, opinar y emitir recomendaciones respecto de la administración y operación del Registro de OSCs, así como concurrir anualmente con la Comisión de Fomento para realizar una evaluación conjunta de las políticas y acciones de fomento.

La ley reconoció derechos especiales para las OSCs, de acuerdo con su naturaleza asociativa, entre los que destacan el derecho a incidir en las políticas públicas, el derecho a participar en consultas, el derecho al respeto de su autonomía interna. Tanto o más significativo es la definición legal de los apoyos y estímulos a las organizaciones, que pueden ser de tipo económico, ya en dinero o en especie, o bajo formas de capacitación presencial o a distancia, asesorías, servicios, difusión y concertación y coordinación.

A su turno, la ley identifica específicas “acciones de fomento” que deben desarrollar los organismos públicos en relación con las OSCs, tales como promoción de la participación de las organizaciones en los órganos, instrumentos y mecanismos de consulta para la planeación, ejecución y seguimiento de políticas públicas; adopción de medidas, instrumentos de información, incentivos y apoyos en favor de las organizaciones; concertación y coordinación con organizaciones para impulsar sus actividades; diseño y ejecución de instrumentos y mecanismos que contribuyan a que las OSCs accedan al ejercicio pleno de sus derechos y cumplan con sus obligaciones; realización de estudios e investigaciones que permitan apoyar a las OSCs en el desarrollo de sus actividades; celebración de convenios de coordinación entre ámbitos de gobierno, a efecto de que estos contribuyan al fomento de las actividades objeto de la ley; y otorgamiento de los incentivos fiscales previstos en las leyes de la materia.

Finalmente, es particularmente relevante en la LFOSC el deber de la Comisión de Fomento, en coordinación con las dependencias y entidades de la administración pública federal, de elaborar y publicar un Informe Anual de las acciones de fomento y de los apoyos y estímulos otorgados a favor de OSCs que se acojan a esta ley, cuestión que ha venido sucediendo periódicamente y generando el necesario debate nacional para mejorar el ambiente legal y sociopolítico para el funcionamiento de las OSCs. El infor- 
me respectivo, consolidado por la Secretaría de Hacienda, debe ser incluido como un apartado específico del Informe Anual que rinde el Presidente de la República al Congreso de la Unión y de la Cuenta Pública elaborada con base en las leyes de Presupuesto, Contabilidad y Gasto Público, de Transparencia y Acceso a la Información, de Fiscalización Superior de la Federación y demás leyes aplicables.

Aunque rica y sugerente en los compromisos públicos que contempla, sin duda, la LFOSC no ha venido a resolver todos los problemas de este amplio sector en México, suscitándose en la actualidad nuevos problemas y un debate en torno a la evaluación de la ley a diez años de su vigencia, con todo, ha sido pionera en encaminarse en una veta conforme con la cual las OSCs se convierten en sujetos facultados para exigir un espacio legitimado de actuación en el desarrollo humano y social y encontrar en los diversos niveles y campos de la administración estatal un interlocutor válido y, eventualmente, un "partner” estratégico para su propio desarrollo en consonancia con el desarrollo de la sociedad toda (Tapia y Verduzco, 2013).

En el caso brasileño, a partir del proceso de redemocratización de mediados de los ochentas, el Estado amplió progresivamente la esfera de interacción con las OSCs, siendo posible identificar tres fases evolutivas: i) redemocratización; ii) participación ciudadana; y iii) contractualización (Storto, 2014; Lopes y otros: 2013).

La fase de "redemocratización” consistió en la definición de la garantía de los derechos a la libertad de creación y de acción de las OSCs, ocurrida durante las décadas del ' 80 y ' 90 . Al efecto, la Constitución Federal de 1988 previó la no interferencia estatal en la creación, funcionamiento y auto-organización de tales entidades. Consolidada la situación anterior, una segunda fase de “participación ciudadana” se inicia con la dinamización del mandato constitucional de participación y control social por representantes de OSCs en el proceso de elaboración, implementación y evaluación de políticas públicas, ejercido en ámbitos tales como planificación municipal, usuarios de servicios públicos, seguridad social, salud, educación, protección del patrimonio cultural, entre otros. La acción de las OSCs bajo esta perspectiva se vio reflejada en su integración en consejos de políticas públicas y, por otra parte en su movilización, incidencia y aportes proposititos en diversas leyes, como la Ley de Recursos Hídricos, la Ley Nacional de Telecomunicaciones, el Estatuto del Niño y del Adolescente, la Ley Orgánica de Asistencia Social, la Ley de Incentivos Fiscales para Proyectos Culturales. El derecho a participar se tradujo en esta fase en el deber del Estado de crear y regular espacios significativos de participación.

Las OSCs brasileñas y el mismo gobierno apuntan actualmente a una nueva fase llamada de “contractualización” caracterizada por la regulación jurídica de las relaciones entre OSCs y órganos del Estado. Este proceso comenzó con la reforma del Estado en los '90 y el reconocimiento de la cooperación de las OSCs como factor decisivo de la "acción pública no estatal” (Bresser y Cunill,2000). En este contexto, se dictaron la Ley 9.637/ 
98 de Organizaciones Sociales y la Ley 9.790/99 de Organizaciones de la Sociedad Civil de Interés Público, que crean instrumentos jurídicos de cooperación y alianza contractual (el contrato de gestión y los "términos de parcería”, respectivamente). Adicionalmente, se pone en ejecución el Sistema de Convenios con la Unión (SICONV), que unifica y reglamenta el ámbito de la contratación Estado-OSCs en un marco de transparencia. Esta fase de contractualización se caracteriza especialmente por la búsqueda de instrumentos para la implementación de programas estatales que efectivicen derechos económicos, sociales y culturales a través de un trabajo conjunto con las OSCs, lo que implica desarrollar alianzas y convenios de transferencia en áreas de servicios no exclusivos del Estado, como la salud y la educación.

La propia jurisprudencia del Tribunal Supremo Federal ha reconocido la dimensión constitucional de esta participación a través de la ejecución directa de acciones en colaboración con el Estado, incluso con la posibilidad de financiamiento público de las OSCs para la realización de servicios de relevancia pública. De este modo, se afirma el deber del Estado brasileño de relacionarse con las OSCs, garantizando su libertad de existencia, de acción y de expresión, al mismo tiempo de su deber de crear espacios para la práctica de la ciudadanía y difundir las buenas prácticas que contribuyan al desarrollo de la sociedad.

De este modo, la dimensión del financiamiento público se conecta en Brasil con el deber del Estado de invertir, directa o indirectamente, a través de incentivos fiscales, mecanismos de exención y simplificación financiera, en la creación y desarrollo de OSCs consideradas esenciales para la vida democrática.

Cabe agregar que en los primeros días del mes de julio de 2014, la Cámara de Diputados federal aprobó el Proyecto de Ley $\mathrm{N}^{\circ} 7.618$, cuya promoción ha sido un emblema de los esfuerzos de colaboración entre las OSCs y el Ejecutivo federal en Brasil, en términos del planteamiento de un adecuado marco regulatorio para las OSCs, capaz de generar un ambiente habilitante para su desarrollo libre e independiente y, desde esta premisa, a la vez cooperador con las políticas públicas. Este proyecto de ley busca establecer "el régimen jurídico de las alianzas (o parcerias) voluntarias, que pueden incluir o no transferencias de recursos financieros, entre la Administración Pública y las organizaciones de la sociedad civil, en régimen de mutua cooperación, para la consecución de finalidades de interés público”; definir "directrices para la política de fomento y de colaboración con organizaciones de la sociedad civil” y establecer "el registro de colaboración y el registro de fomento” respectivamente. Inspira esta nueva legislación el reconocimiento pleno de los derechos fundamentales de las OSCs en tanto personas jurídicas sin fines de lucro, y un imperativo de no retroceso, es decir, que los avances en la regulación legal y contractual de estas alianzas, asociaciones y otras formas de cooperación "contractual” con el Estado no limiten la dimensión de autonomía de las organizaciones (Storto, 2014: 37). Por tanto, al reglar las condiciones de acceso a instancias y mecanismos de 
participación, financiamiento o contratación, dicha autonomía y el respeto a la personalidad propia de las OSCs deben ser plenamente asegurados y promovidos.

Finalmente, otro modelo digno de ser explorado y que puede aportar lecciones a iniciativas en Chile es el que provee la legislación española, con la Ley Nº 38, General de Subvenciones, de 2003, y su Reglamento. Esta ley ha sido replicada con variantes en diversas Autonomías y sirve de marco general para la cooperación entre el Estado y las OSCs, la provisión de servicios de interés público por parte de estas, de acuerdo con un amplio concepto de políticas públicas que deja espacio a su desarrollo con autonomía y flexibilidad creativa. Esta normativa se complementa con el Real Decreto-ley $N^{\circ}$ 7, de reciente dictación (2013), que trata de medidas urgentes de naturaleza tributaria, presupuestaria y de fomento de la investigación, el desarrollo y la innovación y que, entre otras cosas, regula el reconocimiento de las "entidades del tercer sector colaboradoras de la Administración general del Estado". La integración sistémica de esta normativa se puede comprobar toda vez que se consideran como "actividades de interés general”, requisito esencial para el referido reconocimiento, las previstas en el artículo 4 de la Ley $\mathrm{N}^{\circ}$ 6, de 1996, del Voluntariado.

En su preámbulo el ya citado Real Decreto-ley Nº 7 declara:

“...Por otra parte, se hace inaplazable el reconocimiento jurídico del papel esencial que determinadas organizaciones y entidades sin ánimo de lucro tienen a la hora de dar respuesta a las necesidades cada vez más acuciantes de la sociedad, colaborando directamente con las Administraciones Públicas, quedando al mismo tiempo garantizada la vía de canalización de los fondos públicos imprescindibles para que las mismas puedan cumplir y desarrollar los fines que les son propios”, lo que denota un compromiso entre las necesidades estatales de ejecutar sus políticas y la valoración de la identidad irreductible de las OSCs llamadas a desarrollar "los fines que les son propios”.

Por otra parte, el reconocimiento como entidad colaboradora de la Administración del Estado no afecta solamente a las OSCs que pretendan solicitar la asignación tributaria del impuesto a la renta (IRPF) para fines sociales, que era el propósito inicial del legislador. Además de ello, las entidades a las que se les reconoce dicho estatus pueden situarse en una posición prevalente en la relación con las Administraciones públicas, no solo desde el punto de vista de las ayudas y subvenciones, sino que desde la interlocución sociopolítica ante el Estado.

Tornando a la Ley de Subvenciones, de acuerdo con su exposición de motivos, esta se funda en principios de estabilidad presupuestaria y transparencia pública y reconoce la atribución constitucional de las Administraciones Públicas, tanto la central como las descentralizadas, para desa- 
rrollar acciones por la vía de subvenciones a entes privados con y sin fines de lucro, diferenciando las competencias centrales, las de las Autonomías y las de los municipios. Legalmente se requiere de los órganos de las respectivas Administraciones la definición de un plan estratégico de subvenciones y de un sistema de seguimiento.

Las subvenciones son concebidas como colaboración entre la Administración Pública y los particulares, precisando la ley el tenor de la "relación jurídica subvencional”, que se encuentra afecta a determinados objetivos, requisitos, procedimientos y sistemas de control y evaluación.

La ley española no abriga misterios en cuanto a que el régimen general de las subvenciones a entes privados se estructura sobre un sistema de “concurrencia competitiva”, en que la selección de los postulantes se efectúa bajo condiciones de igualdad, publicidad y objetividad. Adjudicada una subvención, se generan obligaciones financiero contables y de registro para las organizaciones. A su turno, la ley regula el gasto subvencionable y sus límites, se tipifica infracciones y se prevé sanciones para hacer valer la responsabilidad de las OSCs, junto con el reintegro del monto de los recursos.

Gran parte de las OSCs españolas que desarrollan sus actividades dentro del territorio español tienen entre sus principales fuentes de financiamiento el sistema de subvenciones conectado al presupuesto de las Administraciones Públicas españolas (en un circuito diferente se sitúan las llamadas “Organizaciones No Gubernamentales de Desarrollo”, que prestan su acción fuera del país y funcionan en torno a la cooperación internacional oficial del Estado Español, canalizada principalmente a través de la Agencia Española de Cooperación Internacional para el Desarrollo, AECID).

Se debe advertir como una particularidad de la ley española de subvenciones el hecho de que no distingue entre organizaciones sin fines de lucro y entidades lucrativas. El sistema se especifica con otras regulaciones como el ya referido reconocimiento de entidades colaboradoras del Estado y otros registros y sistemas objetivos de selección. Con todo, de acuerdo con el ámbito del quehacer de los diferentes órganos estatales, son habituales los llamamientos periódicos dirigidos particularmente a las OSCs “sin fines de lucro". En este sentido, destaca, por ejemplo, el Ministerio de Sanidad, Servicios Sociales e Igualdad que enumera las entidades que pueden postular a subvenciones: organizaciones sin fines de lucro del tercer sector colaboradoras de la administración del Estado, ONGs vinculadas a la cooperación internacional, la Cruz Roja Española, y agrupaciones de OSCs sin personalidad jurídica.

Este Ministerio determina como requisitos de postulación que se trate de programas de interés general que correspondan a la administración central del Estado o con requisito de supraterritorialidad, orientados a medidas para la ordenación básica del sector o que aseguren iguales posibilidades para sus potenciales destinatarios en todo el territorio nacional, todo 
lo anterior en torno a 14 ejes temáticos: infancia y familia; jóvenes; mujeres; personas mayores, personas con discapacidad, personas con problemas de drogodependencia, pueblo gitano, personas inmigrantes, personas afectadas por VIH/SIDA, personas reclusas y ex-reclusas, atención a situaciones de urgencia, atención a la inclusión social, intervención directa del voluntariado, igualdad de trato y no discriminación.

\section{Una propuesta institucional para la sustentabilidad de las OSCs en Chile}

Tomando como base los fundamentos constitucionales y de derechos fundamentales arriba señalados, más las experiencias comparadas y las tendencias que ellas evidencian, se puede tomar pie en el programa de gobierno de la Nueva Mayoría para afirmar que el fortalecimiento de la sociedad civil debe ser elevado a una verdadera política de Estado, reflejada en instituciones públicas, en dispositivos normativos y presupuestarios permanentes, imperativos y relevantes, y en una actitud organizacional y cultural del mismo Estado que facilite la participación ciudadana a través de las OSCs de una manera integral, transversal y coordinada.

Si bien la idea de fortalecimiento de las OSCs no se agota en la sustentabilidad económica, esta es sin duda un pilar que no se debe obviar y que en las actuales circunstancias resulta crítico y, por ende, urgente de abordar estructuralmente.

Al efecto, coincidimos en que una estrategia integral de fortalecimiento de la sociedad civil, como la que el mencionado Programa de gobierno propone, implica la redefinición de los objetivos, los montos y formas de asignación del actual Fondo de Fortalecimiento de las Organizaciones de Interés Público, creado por la Ley 20.500, de 2011.

Asimismo, coincidimos en la necesidad de crear una institucionalidad propia que dé fuerza y presencia en el Estado a la variable participación y fortalecimiento de la sociedad civil. Ello ha de materializarse en un Consejo de Participación Ciudadana y Fortalecimiento de la Sociedad Civil, conformado por representantes de la ciudadanía organizada y de los poderes del Estado, con mayoría de los primeros.

Dicho Consejo debe ser concebido como el ente rector de las políticas de Estado en materia de fortalecimiento de la participación ciudadana y de la sociedad civil, es decir, ha de encargarse de definir, diseñar e implementar dichas políticas en el seno de la administración del Estado y configurar una relación constructiva y plural con los variados sectores, colectivos sociales y ámbitos del quehacer nacional, incluyendo los sectores privados con y sin fines de lucro e, incluso los movimientos sociales, en lo que fuere pertinente. Además, debe encargarse de la educación, difusión y promoción de los derechos inmediatamente vinculados al ejercicio de la participa- 
ción social y ciudadana (libertad de expresión, derecho a la igualdad, derecho a la información, derecho de petición y a ser oído, derechos de reunión y asociación, entre los más significativos).

En un nivel más operativo, dicho Consejo deberá coordinar un sistema integral de participación ciudadana a nivel nacional, del que formarán parte todos los consejos de la sociedad civil creados bajo el amparo de la Ley 20.500, con especial mirada a su desarrollo en las regiones y comunas.

Dicho Consejo deberá elaborar un informe anual, periódico, sobre el estado del ejercicio del derecho a la participación y sobre la vida organizacional ciudadana en el país, uno de cuyos productos será el "Índice de Participación Ciudadana” que, con metodologías asentadas por las recientes experiencias de observatorios y auditorías sociales y de derechos, dé cuenta y evalúe los avances y dificultades en la materia, así como la difusión de buenas prácticas colectivas.

Una objeción previsible y fundada, por cierto, en un riesgo evidente, es que un esquema tal de Consejo de Participación Ciudadana y de Fondo de Fortalecimiento respectivo "institucionalice" y burocratice (en sus peores versiones), o funcionalice o capture en provecho del gobierno de turno o de segmentos particulares en el Estado, el fenómeno y los agentes sociales eminentemente independientes, irreductibles y "líquidos" de la sociedad civil. Se debe aclarar que la concepción y eventual diseño de este Consejo no corresponde a ni tiene vocación de convertirse en un Ministerio. Se trataría de un organismo autónomo del Estado, independiente pero relacionado con el Poder Ejecutivo, con personalidad jurídica de derecho público, atribuciones legales y patrimonio propio, al modo como lo son, por ejemplo, la Corporación Nacional de Desarrollo Indígena (CONADI), el Consejo para la Transparencia o el Instituto Nacional de Derechos Humanos (INDH), sin pretender que alguno de estos configure un modelo ideal ni mucho menos. Por otra parte, y aunque no tienen personalidad jurídica de derecho público, el diseño puede tomar, además, elementos de modelos tales como la Comisión Nacional de Investigación Científica y Tecnológica (CONICYT) y el Consejo Nacional de la Cultura y las Artes. Todas estas instituciones, si bien cumplen funciones públicas muy diversas, tienen la particularidad de estar dotados de estatutos autónomos bien desarrollados que aseguran o debieran asegurar su autorregulación y buen funcionamiento, en especial la expresión plural de los actores concernidos y el procesamiento democrático de las decisiones y eventuales conflictos, evitando la cooptación o funcionalidad acrítica ante un determinado gobierno. Dentro de ese marco, estos organismos están encabezados por cuerpos directivos colegiados cuyos miembros proceden total o parcialmente de la elección o designación de sectores representativos, ya sea política o culturalmente, o bien de la comunidad de pares respectiva. La existencia de un director o secretario ejecutivo unipersonal tiene su contrapeso en el respectivo consejo directivo cuyos acuerdos y directrices deben seguir, en tanto órgano normativo y de control. Por tanto, la ingeniería institucional 
del futuro Consejo para la Participación y el Fortalecimiento de la Sociedad Civil no parte de cero en esta materia.

Especial atención merece en todo caso el modelo del referido Instituto Nacional de Derechos Humanos, que recoge en buena medida las recomendaciones de Naciones Unidas sobre instituciones autónomas de derechos humanos como factor fundamental que asegura el control sobre la acción de los gobiernos. La analogía que puede establecerse es que la noción de derechos humanos, de modo similar a la de "sociedad civil", es irreductible a su absorción, mimetización o manipulación dentro o por el Estado sin que se produzca su inmediata desnaturalización y consecuente deslegitimación. Aunque las concreciones institucionales suelen estar lejos de la perfección, cabe aspirar a que en materia de expresión genuina de la sociedad civil ocurra lo que también se espera, por ejemplo, en materia de derechos humanos, pueblos indígenas, deportes, ciencia o cultura, esto es, que el Estado no desnaturalice o corrompa su desarrollo autónomo.

Tornando a la necesidad de un rediseño del Fondo de Fortalecimiento actualmente existente, este implica emigrar su dependencia actual de la Secretaría General de Gobierno que, como sabemos, se trata de un ministerio altamente sensible a las coyunturas políticas, que históricamente ha tenido la administración de las relaciones y la interlocución con el mundo social organizado, no exentas de sesgos y riesgos de clientelismo y favoritismo y que, por lo demás, siendo el ministerio encargado de la vocería del gobierno central y, particularmente, de la Presidencia de la República, no logra ubicar satisfactoriamente entre sus prioridades las necesidades y demandas de las OSCs chilenas y de los movimientos que estas configuran.

En tal sentido, una opción a discutir en profundidad es que el referido Consejo de Participación Ciudadana y Fortalecimiento de la Sociedad Civil disponga de una división cuya autonomía, objetividad y probidad se asegure institucionalmente y que se encargue de la gestión superior del Fondo de Fortalecimiento de las Organizaciones de Interés Público.

Supuestas sus transformaciones orgánicas, estructurales y funcionales, y bajo condiciones de objetividad e igualdad de trato, relevancia financiera y descentralización, el Fondo de Fortalecimiento está llamado a ser una de las grandes herramientas de sustentabilidad económica de las OSCs chilenas que posean esa clase de objetivos ("de interés público", según lo define el artículo 15 de la Ley 20.500), sin exclusiones. Es un dato suficientemente asentado que en países de renta media o incluso media alta, como la OCDE considera a Chile y a algunos países del Cono Sur, la cooperación internacional no puede ser la base de financiamiento de las OSCs. En estas circunstancias, y asumiendo que la autosostenibilidad a través de la venta de bienes y servicios o del pago de cuotas sociales no representa para la mayoría de las organizaciones una opción estratégica relevante ni universalizable, las OSCs chilenas están en cierto modo obligadas a dirigir su demanda de sustentabilidad a una redistribución efectiva del producto social del país. Esto implica apuntar a recursos públicos, ya 
sea provistos por el Estado directamente a través de la figura de fondos públicos y subvenciones, o indirectamente, a través del flujo de las donaciones sujetas a beneficios tributarios, en un esquema de efectiva ampliación y democratización de esta última opción, como se verá en el apartado siguiente.

Retomando la estrategia para perfilar estas propuestas en el debate público, se debe tener en cuenta que la vigencia de la Ley 20.500 ha desencadenado un proceso de instalación de Consejos de la Sociedad Civil en ministerios y servicios públicos, así como en los municipios del país (Marín y Mlynarz,2013). Esto da pie para establecer el desafío de potenciar, expandir y hacer redituar positivamente el caudal participativo de las OSCs, activando con solvencia la sinergia entre estos órganos y sus entramados locales, regionales y nacionales más allá del carácter meramente consultivo que les asigna la ley, el que puede ser superado política y culturalmente desarrollando el amplio potencial de sus funciones como interfaces socioestatales o público-privados (Hevia, 2007) legitimados y efectivamente incidentes en los diversos ámbitos de la toma de decisiones públicas.

El desafío es que las autoridades al frente de los Consejos de la Sociedad Civil tomen en serio y asuman que el éxito y eficacia de su gestión están indisolublemente ligados al factor participación ciudadana, esto es, a las funciones de voz y opinión, de formulación de diagnósticos y propuestas, de debate, deliberación y fiscalización ejercitadas por dichos Consejos, en el marco de una política global de reconocimiento y fortalecimiento de la sociedad civil, según se señaló más arriba.

\section{Financiamiento a través de franquicias tributarias}

Como complemento del análisis precedente, corresponde señalar, aunque sea someramente, un segundo vector del financiamiento público de las OSCs. El sistema de tributación en Chile entregó el año 2013 \$ 7.657.541.138 a organizaciones sin fines de lucro. Este modelo expresado en exenciones tributarias, rebajas de base imponible y créditos a las donaciones beneficia básicamente a empresas. La información disponible evidencia que una parte sustancial de las grandes instituciones receptoras está constituida por fundaciones ligadas a los gremios empresariales, corporaciones ligadas a los gobiernos municipales y entidades vinculadas a la Iglesia, sin considerar el caso específico de las universidades privadas creadas al amparo del D.F.L. N ${ }^{\circ} 1$ del Ministerio de Educación, de 1981, que cuentan con el dispositivo del artículo 69 de la Ley 18.681 de 1987, que les permite acceder a donaciones con beneficios tributarios para sus donantes. En este sentido, los datos muestran un "mercado filantrópico” altamente concentrado, que para la enorme mayoría de las organizaciones de la sociedad civil chilenas ha resultado de hecho inaccesible. Lo anterior denota una particular y rígida estructura económica y sociocultural de circuitos de instituciones y de empresas y empresarios que generan flujos significativos de recursos orientados hacia un número relativamente pequeño de organizaciones, 
la mayoría de ellas de carácter benéfico o asistencial con sesgo confesional o conservador. A esta tendencia, que podría llamarse "histórica", se une en las últimas décadas otra que inspirada en determinadas visiones de ética o responsabilidad empresarial, muestra un importante caudal de donaciones efectuadas a fundaciones creadas o ligadas, por propiedad o interés, a las propias empresas donantes. Se trataría de la extensión de estrategias empresariales hacia la promoción del capital humano y del bienestar de las comunidades en las que están insertos o que les sirven productivamente. He aquí un problema complejo de resolver en aras de una universalización y democratización de las donaciones con beneficios tributarios en Chile.

Recogiendo una trayectoria reciente, que tiene entre sus antecedente la dictación en 1990 de la llamada "Ley Valdés" sobre donaciones con fines culturales (art. $8^{\circ}$ de la ley 18.985), las décadas de los noventas y del 2000 dieron paso a nuevas leyes de donaciones como la Ley 19.247 de 1993, de Donaciones con Fines Educacionales y la Ley 19.712 de 2001, que junto con crear la institucionalidad pública del deporte y reconocer las organizaciones deportivas, contiene normas sobre donaciones con fines deportivos. Investigaciones previas (Irarrázaval y Guzmán, 2000) y estudios preparatorios, encargados por la División de Organizaciones Sociales (DOS) que posteriormente dieron lugar al proyecto de ley sobre asociaciones y participación ciudadana (Viveros y otros, 2003), habían llamado la atención de las OSCs sobre esta temática estratégica como fuente de financiamiento y de colaboración público-privada.

Un hito importante de este itinerario fue la dictación en 2003 de la Ley 19.885 que regula "el Buen Uso de las Donaciones que dan origen a Beneficios Tributarios y los extiende a otros Fines Sociales y Públicos”, que incorporó al circuito filantrópico tributario a un sector de OSCs de alta significación social, esto es, las dedicadas a enfrentar la pobreza, la discapacidad y la exclusión social. Con todo, es sintomático que esta iniciativa legislativa se originó en la propuesta de promover las donaciones a campañas electorales y partidos políticos, cosa que efectivamente también reguló, pero que no es materia de este trabajo. La misma ley creó el "fondo mixto de apoyo social” con una fracción de las donaciones (33\%) que los contribuyentes hacían a las OSCs de su preferencia, operando como mecanismo de compensación y equidad. De esta manera y a través de otras reglas, límites y controles, la Ley 19.885 pretendió introducir una ampliación de espacios, dinamismo, control y transparencia al sistema de donaciones con renuncia fiscal, pero el rigor de parte de su normativa terminó por confundir y generar incertidumbres y temores, inhibiendo en buena medida y por un tiempo considerable la voluntad de los donantes.

Sin embargo, la necesidad de reactivar y hacer fluida la veta de las donaciones de empresas privadas motivó a un conjunto de organizaciones concernidas en esta materia ${ }^{2}$ y a un conglomerado articulador de varias de ellas, la Comunidad de Organizaciones Solidarias, a incidir en que sucesivos gobiernos introdujeran reformas de perfeccionamiento a la Ley de donaciones con fines sociales en los años 2009 y 2012, además de reformar- 
se profundamente la ley de donaciones con fines culturales en el año 2013, ampliando los criterios sobre organizaciones e instituciones beneficiarias, en las opciones de uso de los recursos donados y la opción de que contribuyentes personas naturales también puedan donar accediendo a los incentivos legales.

Siguiendo con este proceso, recientemente, el mismo conjunto de fundaciones y OSCs colaboró activamente en la elaboración de una propuesta legislativa orientada a crear un régimen unificado para los beneficios tributarios por donaciones efectuadas a entidades sin fines de lucro, que regule los requisitos y límites de donantes, donatarios y montos, la institucionalidad, el funcionamiento, los efectos tributarios, la contabilidad, la auditoría y la fiscalización de estas operaciones (Boletín N ${ }^{\circ}$ 9266-05, ingresado a la Cámara de Diputados el 6 de marzo de 2014).

El fundamento de esa propuesta se encuentra en que gran parte de las OSCs no accede al financiamiento por vía de las donaciones, entre otros factores por lo engorroso del sistema que requiere tener la capacidad de encontrar, estudiar y entender más de 90 cuerpos normativos de alta complejidad, que suman más de 1000 páginas, dictados en un período de 40 años y, además, sin que estos puedan encontrarse de manera ordenada y sistematizada.

Desde nuestra perspectiva, creemos que se puede agregar una serie de otras definiciones que lleve a contar con un sistema de incentivos tributarios que permita beneficiar a un mayor número de organizaciones, para lo cual debería homogeneizarse en los diversos cuerpos legales atingentes el tipo de OSC, bajo cuya acreditación se permita reconocer a toda posible beneficiaria de donaciones vinculadas a beneficios tributarios sin exceso de tramitación burocrática. En tal sentido, el concepto y definición de “organizaciones de interés público” contenido en la Ley 20.500 debería universalizarse en toda la legislación nacional, tanto de derecho público como de derecho privado, y trascender su actual encapsulamiento a potenciales beneficiarias de un fondo público en particular. De esta forma se resguardaría efectivamente los principios de legalidad, de igualdad, de transparencia, de participación y de colaboración y fortalecimiento de las OSCs, apuntados más arriba, que informan esta gravitante materia de las relaciones entre el Estado chileno y la ciudadanía organizada.

Por ejemplo, un tema novedoso y no explorado en la agenda de las OSCs en Chile, y que creemos puede tener insospechados efectos positivos, es cuestionar el carácter restrictivo que tienen actualmente los incentivos tributarios en relación con las personas naturales (salvo en la Ley de Donaciones Culturales con la reforma de 2013). Esta limitación puede explicar en gran medida la alta concentración de las donaciones en nuestro país y su sesgo elitista y regresivo. ${ }^{3} \mathrm{La}$ experiencia comparada muestra que las empresas tienden a donar a las organizaciones afines, mientras que un modelo que diversifica y hace más plural y eficiente la recaudación de donaciones es aquel que se sustenta en las donaciones que realizan las 
personas individuales (Irarrázaval y Guzmán, 2000: 218). En Estados Unidos el dinamismo e independencia de la sociedad civil está determinado justamente por las donaciones de las personas naturales(Hodgkinson y otros, 1996), de tal modo que el $80 \%$ de las donaciones proviene de las personas individuales, mientras que las donaciones de empresas no superan el 5\%(Salamon y otros, 1995).

Por otra parte, la admisión de exenciones, incentivos o franquicias tributarias en Chile tiende a entregarse solo en beneficio de cierto tipo de organizaciones o actividades bastante restringidas y, además, de modo discrecional. Por ejemplo, el artículo $40 \mathrm{~N}^{\circ} 4^{\circ}$ de la Ley de la Renta exime del impuesto de primera categoría a las "instituciones de beneficencia que determine el Presidente de la República”, las que pueden "impetrar este beneficio" en tanto "no persigan fines de lucro y que, de acuerdo a sus estatutos, tengan por objeto principal proporcionar ayuda material o de otra índole a personas de escasos recursos económicos" (Ley de la Renta, art. 40 $\left.\mathrm{N}^{\circ} 4\right)$. De acuerdo con el mismo artículo 40 , en su $\mathrm{N}^{\circ} 3^{\circ}$, también están exentas de dicho impuesto "las instituciones de ahorro y previsión social que determine el Presidente de la República, la Asociación de Boy Scouts de Chile y las instituciones de socorros mutuos afiliadas a la Confederación Mutualista de Chile”. Por su parte, el artículo $31 \mathrm{~N}^{\circ} 7^{\circ}$ de esta misma ley permite al contribuyente de primera categoría que declare renta efectiva, acreditada según contabilidad fidedigna y completa, rebajar de su base imponible determinadas donaciones, en primer lugar aquellas "cuyo único fin sea la realización de programas de instrucción básica o media gratuitas, técnica, profesional o universitaria”. A renglón seguido, el legislador vuelve a individualizar particularmente a organizaciones beneficiarias de estas donaciones: los Cuerpos de Bomberos de la República, el Fondo de Solidaridad Nacional, el Fondo de Abastecimiento y Equipamiento Comunitario, el Servicio Nacional de Menores y los Comités Habitacionales Comunales. Se aprecia la discutible técnica legislativa de precisar individualizadamente las organizaciones beneficiarias, que tiende a la obsolescencia de esta clase de listados, toda vez que menciona algunas organizaciones actualmente inexistentes.

Más allá de estas deficiencias, como ya se dijo, no se ve por qué no podrían ser incluidas en esta clase de beneficios las organizaciones de interés público reconocidas por la Ley 20.500. Así, en vez de entregar al Presidente de la República la facultad discrecional para eximir del impuesto de primera categoría, o entregar al legislador la misma facultad de designar organizaciones beneficiarias "con nombre y apellido", simplemente se debería señalar: i) que estarán exentas de este impuesto y ii) que podrán recibir donaciones afectas a deducciones tributarias en favor de los contribuyentes donantes, las organizaciones de interés público registradas en conformidad a la ley. Esta es la fórmula, por lo demás, que utiliza la legislación española (Cruz y López, 2004).

Consecuentemente, el cambio de sujeto donante de empresas a personas naturales (que tributan sus rentas del trabajo dependiente o inde- 
pendiente en segunda categoría, o bien en el impuesto global complementario) y la universalización de los donatarios que habilite a las OSCs calificadas como "de interés público" y dedicadas a todo tipo de causas sociales sin exclusión (por ejemplo, filantrópicas, caritativas, prestadoras de servicios, comunitarias, de emprendimiento, de investigación, de advocacy, de control ciudadano, de defensa y promoción de derechos,incluso reivindicativas, contestatarias, de expresión de identidades sociales y culturales, o de formas alternativas de vida, etc.) modificaría sustancialmente la actual estructura de donaciones, acusada de una manifiesta regresividad distributiva, con el agravante de la renuncia fiscal implicada en ellas.

Finalmente, desde el punto de vista del uso de nuevas tecnologías, la configuración de plataformas informáticas “amigables” para materializar las donaciones (que debería crear el Servicio de Impuestos Internos) es clave para el éxito de esta forma de financiamiento, así como la realización de campañas de sensibilización de los ciudadanos/as, suficientemente plurales e infomativas, que los motiven a donar. Estos dispositivos sencillos de implementar permitirían que las OSCs se posicionen más de cara a la ciudadanía que al Estado, y que cuando miren al Estado sea, más que reclamando de este autonomía, financiamiento y derecho a la crítica de lo establecido, lo hagan exhibiendo tales atributos. 


\section{Notas}

${ }^{1}$ Sentencias del Tribunal Constitucional No 252/1997, c. 7 y No 467/2006, c. 14 .

${ }^{2}$ Se puede mencionar entre estas entidades, a riesgo de omitir algunas, a Fundación Minera Escondida, Fundación ProHumana, Fundación Pro Bono, Fundación Para la Superación de la Pobreza, Protectora nacional de la Infancia, Fundación Simón de Cirene, Fundación Hogar de Cristo, entre varias otras.

${ }^{3}$ Sobre el carácter elitista y regresivo de las donaciones a las OSCs en Chile ver diagnóstico que establece el Mensaje de la 19.885/2003 que incentiva y norma el buen uso de Donaciones. 


\section{Bibliografía}

Brown, D.L. y Korten, D.C. (1989),Understanding voluntary organizations: Guidelines for donors. WPS 258, Country Economics Department, The World Bank, Washington, DC.

Bresser, L. C. y Cunill N., [eds].(2000), Lo público no estatal en la reforma del Estado, Paidós - Centro Latinoamericano de Administración para el Desarrollo (CLAD), Buenos Aires.

Cea, J. L. (1999),El sistema constitucional de Chile. Síntesis crítica, Facultad de Ciencias Jurídicas y Sociales, Universidad Austral de Chile, Valdivia.

Cruz, M. y López, S. (2004),La fiscalidad en entidades sin ánimo de lucro: estímulo público y acción privada, CIDEAL, Madrid.

De La Maza, G. (2005),Tan lejos tan cerca. Políticas públicas y sociedad civil en Chile, LOM Ediciones, Santiago.

Ídem. (2009), Las ONG, Sociedad Civil y Democracia en Chile Post autoritario. En B. Sorj, (ed), Usos, abusos y desafíos de la sociedad civil en América Latina. Siglo XXI, Buenos Aires.

García, W. (2012), “La subvención administrativa: concepto y régimen jurídico”, Revista de Derecho de la Escuela de Postgrado, U. de Chile, N² Santiago.

Gazmuri, C. (1999),El “48” chileno. Igualitarios, reformistas, radicales, masones y bomberos, Ed. Universitaria, $2^{a}$ ed., Santiago.

Hevia, F. (2007), “Participación ciudadana institucionalizada y despolitización: Análisis crítico de los marcos legales de la participación en América Latina”, México DF, (sin editar).

Hodgkinson, V., Weitzman, M. y Otros (1996), Nonprofit Almanac. Independent Sector.Jossey-Bass Publishers.

Illanes, M. A. (2003), “La revolución solidaria. Las sociedades de socorros mutuos de artesanos y obreros: un proyecto popular democrático 18401910”, en Chile des-centrado: Formación socio-cultural republicana y transición capitalista 1810-1910, LOM, Santiago.

Irarrázaval, I. y Guzmán, J. (2000), “Incentivos tributarios para instituciones sin fines de lucro: análisis de la experiencia internacional“, Estudios Públicos N 77, Santiago, p. 203-274.

Irarrázaval, I. y otros (2006),Estudio Comparativo del Sector Sin Fines de Lucro en Chile, Proyecto Sociedad Civil Global - Sección Chile, Johns Hopkins University - FOCUS, Santiago. 
Isunza, E. (2007), "El reto de la confluencia. Las interfaces socioestatales en el contexto de la transición política mexicana (dos casos para la reflexión)”, en La disputa por la construcción democrática en América Latina, Fondo de Cultura Económica, CIESAS, Universidad Veracruzana, p.281-286.

Lopes, L. y otros (2013), “As Parcerias entre o Estado e as Organizaçôes da Sociedade Civil no Brasil: A formaçâo de uma agenda de mudança institucional e regulatória”, Novena Conferencia Regional International Society for the Third Sector Research, ISTR-LAC, Santiago de Chile, (sin editar).

Marín, T. y Mlynarz, D.(2013), “Balance de la implementación de la ley de participación ciudadana a nivel municipal”, en De la Fuente, G. y Mlynarz, D. El pueblo unido, Mitos y realidades sobre participación ciudadana en Chile, Eds. Universidad Alberto Hurtado, Santiago.

Pearce, J. y otros (2002),Desarrollo, ONG y Sociedad Civil, Intermón/ Oxfam, Barcelona.

Programa de las Naciones Unidas para el Desarrollo (2000),Informe de Desarrollo Humano. Más sociedad para gobernar el futuro, PNUD, Santiago.

Ídem. (2014), Auditoría a la Democracia: Más y Mejor Democracia para un Chile Inclusivo, Santiago.

Salamon, L., Anheier, H.; Sokolowski, W. Y Associates (1995), “The emerging sector: A statistical supplement”. The Johns Hopkins comparative Nonprofit Sector Project.

Salamon, L. y otros. (2004),Dimensions of the Nonpro?t Sector, Volume Two, Kumarian Press, Bloom?eld, USA.

Salazar, G. (2012),Movimientos Sociales en Chile, trayectoria histórica y proyección política. Uqbar editores, Santiago.

Salinas, M (1980),El laicado católico de la Sociedad Chilena de Agricultura y Beneficencia 1838-1849, Universidad Católica de Chile, Santiago.

Sánchez, Alicia y otros (2015), “Diagnóstico, Mapeo y Sistematización de Mecanismos Públicos de Financiamiento hacia las O.S.C. en Chile” en http:/ /accionag.cl/wp-content/uploads/2014/12/Estudio-Diagnostico-Mapeo-ySistematizacion-de-Mecanismos-Publicos-de-Financiamiento.pdf

SecretariaGeral da Presidência de la República - Brasil (2014),Marco Regulatório das Organizaçôes da Sociedade Civil. Disponible en http:// www.secretariageral.gov.br/mrosc

Seoane, J. y otros. (2003),Movimientos Sociales y conflicto en América Latina, CLACSO, Buenos Aires. 
Silva, A. (1997),Tratado de Derecho Constitucional, tomo III, La Constitución de 1980. Antecedentes y génesis, Editorial Jurídica de Chile, Santiago.

Soto, F. (2013), El desafío de la participación: Estudio comparado sobre el referéndum y la iniciativa legislativa popular en América Latina y Europa, LOM, Santiago.

Storto, P. (2014),Informe sobre el Marco Jurídico de las Organizaciones de la Sociedad Civil en Brasil, preparado para el Proyecto Regional de la Mesa de Articulación de Plataformas de OSC de América Latina y el Caribe (sin editar), Sâo Paulo.

Tapia, M. Y Verduzco M. (2013), Fortalecimiento de la ciudadanía organizada: Diagnóstico y reformas para un ambiente propicio en México, Alternativas y Capacidades A.C., México D.F.

Viveros, F. (1998), “La participación de la sociedad civil en acciones de interés público”, en Ciudadanía e interés público: Enfoques desde el derecho, la ciencia política y la sociología, Cuadernos de Análisis Jurídico, Serie Publicaciones Especiales $N^{\circ}$ 8, Facultad de Derecho Universidad Diego Portales, Santiago.

Ídem (2002), "Estado y legalidad, el peso de la noche en la sociedad civil chilena”, En Anuario de Filosofía Jurídica y Social № 20. Sobre la cultura jurídica chilena, Sociedad Chilena de Filosofía Jurídica y Social, Valparaíso.

Viveros, F y otros (2003): Estudio Análisis de la Legislación Vigente en Chile para Organizaciones de la Sociedad Civil, CIDE-Universidad Alberto Hurtado, Informe final para la División de Organizaciones Sociales ( $\sin$ editar), Santiago.

Verduzco, M. y otros (2009),Fondos públicos para las organizaciones de la sociedad civil, Alternativas y Capacidades, A. C, México D.F. 